Research Article

www.ijrap.net

\title{
EVALUATION OF HONEY INCORPORATED FOOD PREPARATION ON THE BASIS OF GLYCEMIC INDEX AND THEIR ADVOCACY IN IMPAIRED GLUCOSE TOLERANCE Rana Seema ${ }^{1 *}$, Katare Charu ${ }^{2}$ \\ ${ }^{1}$ Research Scholar, Department of Home Science, Government KRG PG Autonomous College, Gwalior, Madhya Pradesh, India \\ ${ }^{2}$ Associate Professor, Department of Home Science, Government KRG PG Autonomous College, Gwalior, Madhya Pradesh, India
}

Received on: 10/08/13 Revised on: 08/09/13 Accepted on: 19/09/13

\author{
*Corresponding author \\ E-mail: katarecs@gmail.com \\ DOI: $10.7897 / 2277-4343.04531$ \\ Published by Moksha Publishing House. Website www.mokshaph.com \\ All rights reserved.
}

\section{ABSTRACT}

Honey is a natural sweetener and it is a nature's gift to mankind. Honey is important edible substance, which contains small amounts of proteins, enzymes, amino acids, minerals, trace elements, vitamins and sugars as major constituents. Honey is frequently used in the Ayurvedic system of medicine as variety of the Ayurvedic preparations are taken along with or in combination with honey. The present study was conducted to determine the glycemic index of food products made with different natural sweeteners including honey. Normal healthy subjects $(\mathrm{n}=10)$ and subjects with impaired glucose tolerance $(\mathrm{n}=10)$ were included in the study and administered with equicarbohydrate quantity of glucose and a food preparation 'sweet roll' containing different sweeteners at fasted state on various days. Monitoring of blood glucose in normal healthy subjects and subjects with impaired glucose tolerance at 0, 30, 60, 90 and 120 minutes indicated a significant difference in incremental area under the curve (IAUC) of glucose and food preparations made with different sweeteners. The mean incremental area under the curve of food preparations was significantly lower $(\mathrm{p}=<$ $0.01)$ than that of glucose in subjects with impaired glucose tolerance as well as normal healthy subjects. At the same time honey incorporated sweet rolls were found to have lower glycemic index when compared to rolls prepared with cane sugar and jaggery. This indicated honey incorporated foods may be occasionally consumed by subjects with impaired glucose tolerance.

Keywords: Honey, Glycemic Index, Impaired Glucose Tolerance

\section{INTRODUCTION}

Honey is a sweet food made by bees using nectar from flowers. Honey has a long history of human consumption, and it is used in various foods and beverages as a sweetener and flavoring agent. It contains mainly carbohydrates. The glycemic index (GI) of honey varies from 32 to 87 , depending on botanical origin and on fructose content ${ }^{1}$. Low glycemic index foods, by virtue of the slow digestion and absorption of their carbohydrate content, produce a more gradual rise in blood sugar and insulin levels and are increasingly associated with health benefits. Low glycemic index foods have thus been shown to improve the glucose tolerance in diabetic subjects. The glycemic index concept was developed in human nutrition in an attempt to characterize foods according to their postprandial glycemic response rather than their chemical composition. Although the GI ranking compares standard carbohydrate portions (usually 25 or $50 \mathrm{~g}$ ) and the amount of food tested to derive the GI may not reflect usual amounts consumed ${ }^{2}$. The glycemic effect of a food in humans is influenced by the nature, the type of carbohydrates, the physical form of the food and processing ${ }^{3}$. Sugar, Jaggery and honey are traditional sweeteners. The traditional use of honey in food preparations has been substituted in most cases by sugar and more recently by various sugar syrups derived from starches. At the same time, as part of the increasing appreciation of more natural products in many countries, honey has been "rediscovered" as a valuable food. It contains up to $38.2 \%$ fructose, $31.3 \%$ glucose, $0.7 \%$ sucrose and approximately $25 \%$ other nutrients ${ }^{4}$. Jaggery is a concentrated product of cane juice without separation of the molasses and crystals. It can vary from golden brown to dark brown in color. Jaggery contains up to 50 $\%$ sucrose, up to $20 \%$ invert sugars with some other insoluble matter such as ash, proteins and bagasse fibers ${ }^{5}$. It is directly consumed by humans and used in animal feed mixtures. Jaggery is often called the medicinal sugar and possesses nutritive properties of high order. The study was undertaken to evaluate glycemic response, determine the glycemic index (GI) and acceptability of the products made with different natural sweeteners so that their beneficial health effect with reference to GI may be understood.

\section{MATERIAL AND METHODS}

A food preparation "sweet roll" was prepared with Bengal gram flour, wheat flour, ghee and different sweeteners like honey, cane sugar and jaggery. All the three combinations of rolls i.e. RH (rolls prepared with honey), RCS (rolls prepared with cane sugar) and RJ (rolls prepared with jaggery) were subjected to organoleptic evaluation for various attributes like appearance, texture, colour, flavour and softness. A 9 point hedonic scale determined organoleptic qualities of various combinations of sweet rolls ${ }^{6}$.

\section{Sensory evaluation of rolls}

The rolls thus prepared were tested by the panel of 10 judges for the organoleptic quality and acceptability. Distinct codes were allotted to the products. The judges were requested to taste the food preparations and award a 
score with reference to a number of attributes viz. appearance, texture, colour, flavour and softness during the testing session and scores were obtained for various organoleptic qualities. This procedure was repeated two more times. Similar scores obtained for sensory attributes in both replications were considered acceptable.

\section{Collection of baseline data and determination of} glycemic index

Subjects in the age group of 35 - 45 years were enrolled in the study. The criterion for screening of the subjects in normal health and subjects with impaired glucose tolerance (IGT) was WHO, 2006. On the basis of this criterion fasting blood sugar (FBS) of about $70-110$ $\mathrm{mg} / \mathrm{dl}$ was considered as normal and FBS of about 111 $125 \mathrm{mg} / \mathrm{dl}$ was considered as impaired glucose tolerance. Among the selected subjects 10 subjects were in normal health and 10 subjects had impaired glucose tolerance (IGT). The subjects were explained the study protocol and a written consent for voluntary participation were obtained. All the subjects were asked to attend the testing session after a $10-12 \mathrm{~h}$ overnight fast on the day when test was to be performed. They have been instructed not to consume unusually large meals, drink alcohol or exercise vigorously on the previous day, and to avoid cycling or walking to the laboratory. On the first day subjects were given the standard or reference carbohydrate i.e. $25 \mathrm{~g}$ glucose dissolved in $150 \mathrm{ml}$ of water. Blood glucose level was measured in capillary whole blood obtained by finger prick (Accu-Chek Roche Diagnostics India Pvt. Ltd, Mumbai, India) in the fasted state at 0 and after $30,60,90$ and 120 minutes on consumption of the reference (glucose) food. Blood glucose curves were constructed and the incremental area under the curve (IAUC) was calculated for reference food (glucose) by the trapezoidal rule ${ }^{7}$. Similar procedure was repeated with all the varieties of test foods (rolls). The rolls in different combinations ( $25 \mathrm{~g}$ carbohydrates) were given during testing sessions against the standard or reference carbohydrate on the following three consecutive days at fasted state. Equicarbohydrate portion of roll was calculated on the basis of carbohydrate content of food items given in Nutritive value of Indian foods ${ }^{8}$.

\section{Calculation of glycemic index}

The Glycemic Index (GI) values were calculated by the method of Jenkins et $a l^{2}$. The glycemic index was calculated by dividing the IAUC for the test food by the IAUC for the reference food and multiplying by 100 for each individual. The following formula was used:

$$
\mathrm{GI}=\frac{\text { IAUC for tested Food }}{\mathrm{IAUC} \text { for Reference Food }} \times 100
$$

IAUC - Incremental area under the blood glucose response curve

Table 1: Nutritional composition of the sweet rolls

\begin{tabular}{|c|c|c|c|}
\hline Nutrients & RH & RCS & RJ \\
\hline Energy (Kcal) & 199.74 & 199.665 & 200.08 \\
\hline Protein $(\mathrm{g})$ & 3.78625 & 3.75875 & 3.79075 \\
\hline Carbohydrate $(\mathrm{g})$ & 25.00325 & 25.00575 & 25.04075 \\
\hline Fat (g) & 9.40175 & 9.40175 & 9.41225 \\
\hline \multicolumn{2}{|c}{ Abbreviation: RH-roll honey, RCS-roll cane sugar, RJ-roll jaggery }
\end{tabular}

Table 2: Sensory evaluation of sweet rolls with three different sweeteners

\begin{tabular}{|c|c|c|c|c|c|c|c|}
\hline S. No. & Combination & Appearance & Texture & Color & Flavor & Softness & Overall acceptability \\
\hline 1 & RH & 8.60 & 8.10 & 8.30 & 8.50 & 8.30 & 8.36 \\
\hline 2 & RCS & 8.60 & 8.20 & 8.40 & 8.60 & 8.40 & 8.44 \\
\hline 3 & RJ & 8.60 & 8.10 & 8.30 & 8.50 & 8.30 & 8.36 \\
\hline
\end{tabular}

Values are given in mean, Abbreviation: RH-roll honey, RCS-roll cane sugar, RJ-roll jaggery

Table 3: IAUC and GI in subjects with IGT and normal healthy subjects

\begin{tabular}{|c|c|c|c|c|c|}
\hline \multicolumn{2}{|c|}{} & \multicolumn{2}{c|}{ IAUC } & \multicolumn{2}{c|}{ GI } \\
\hline S. No. & Products & NHS & IGT & NHS & IGT \\
\hline 1 & Glucose & 175.91 & 319.16 & - & - \\
\hline 2 & RH & $79.16^{*}$ & $120.00^{*}$ & 45.00 & 37.59 \\
\hline 3 & RCS & 114.16 & $121.66^{*}$ & 64.89 & 38.11 \\
\hline 4 & RJ & $108.33^{*}$ & $121.66^{*}$ & 61.58 & 38.11 \\
\hline
\end{tabular}

Values are given in mean $(\mathrm{mg} / \mathrm{dl}),{ }^{*}$ Significant change $\mathrm{P}<0.01$, Abbreviation: IAUC-incremental area under the curve, GI-glycemic index, NHS-normal healthy subjects, IGT-impaired glucose tolerance, RH-roll honey, RCS-roll cane sugar, RJ-roll jaggery

Table 4: Mean (\%) reduction in IAUC of roll varieties compared with IAUC of glucose

\begin{tabular}{|c|c|c|}
\hline \multicolumn{3}{|c|}{ \% Reduction compared to glucose } \\
\hline & NHS & IGT \\
\hline RH & 55.00 & 62.40 \\
\hline RCS & 35.10 & 61.88 \\
\hline RJ & 38.42 & 61.88 \\
\hline
\end{tabular}

Values are given mg/dl, Abbreviation: IAUC-incremental area under the curve, NHS-normal healthy subjects, IGT-impaired glucose tolerance, RH-roll honey, RCS-roll cane sugar, RJ-roll jaggery 


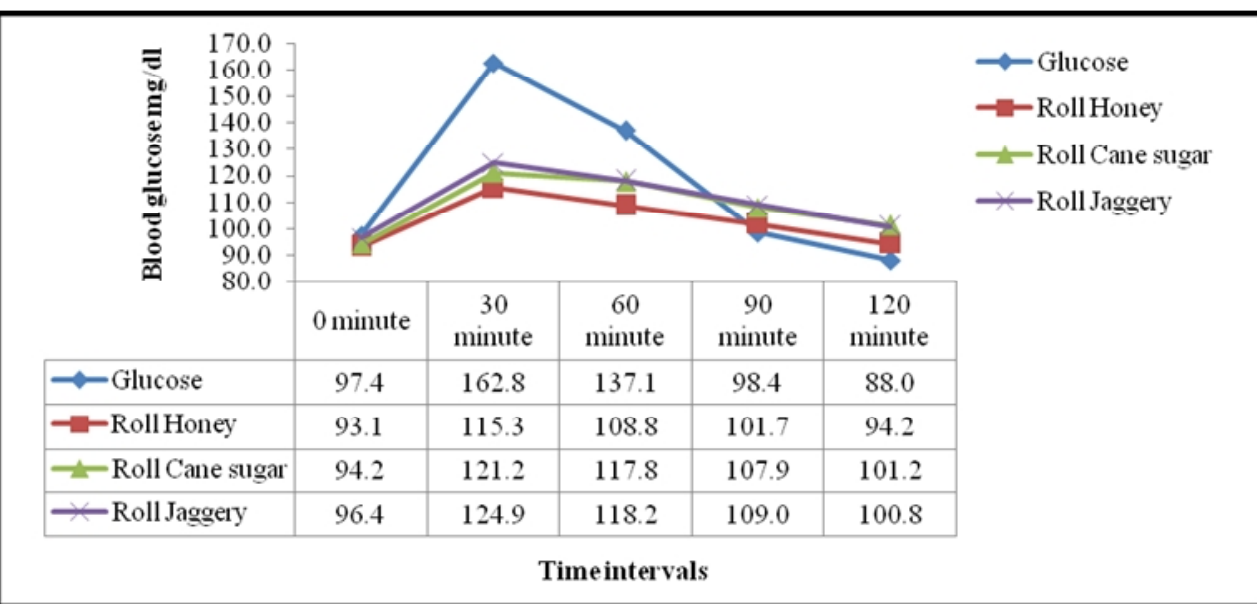

Graph 1: Blood glucose response curve in normal healthy subjects administered with sweet roll varieties

\begin{tabular}{|c|c|c|c|c|c|c|c|}
\hline \multirow[t]{2}{*}{ 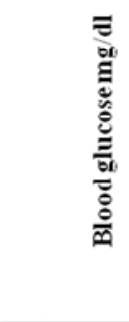 } & $\begin{array}{l}220.0 \\
200.0 \\
180.0 \\
160.0 \\
140.0 \\
120.0\end{array}-$ & & & & & & \multirow[t]{7}{*}{$\begin{array}{l}- \text { Glucose } \\
- \text { Roll Honey } \\
- \text { Roll Cane sugar } \\
- \text { Roll Jaggery }\end{array}$} \\
\hline & & 0 minute & $\begin{array}{c}30 \\
\text { minute }\end{array}$ & $\begin{array}{c}60 \\
\text { minute }\end{array}$ & $\begin{array}{c}90 \\
\text { minute }\end{array}$ & $\begin{array}{c}120 \\
\text { minute }\end{array}$ & \\
\hline \multicolumn{2}{|c|}{$\multimap$ Glucose } & 120.3 & 184.6 & 198.3 & 161.9 & 135.3 & \\
\hline \multicolumn{2}{|c|}{- -Roll Honey } & 114.9 & 133.9 & 147.4 & 131.4 & 121.3 & \\
\hline \multicolumn{2}{|c|}{ - Roll Cane sugar } & 117.0 & 142.0 & 141.4 & 136.7 & 125.3 & \\
\hline \multicolumn{2}{|c|}{$\longrightarrow$ Roll Jaggery } & 114.9 & 133.3 & 147.6 & 133.7 & 120.7 & \\
\hline \multicolumn{7}{|c|}{ Timeintervals } & \\
\hline
\end{tabular}

Graph 2: Blood glucose response curve in subjects with IGT administered with roll varieties

\section{Statistical Analysis}

Statistical analysis was performed by using a Paired $t$ test. Significance level considered was $\mathrm{P}<0.05$. Statistics was performed by Sigma stats software package (3.5).

\section{Institutional ethical committee}

The study design and experimental protocol was approved by ethical committee serial no JU/IHEC/2013-A/18.

\section{RESULTS}

The mean plasma glucose responses after the consumption of glucose and the test foods in normal healthy subjects and IGT (Impaired Glucose Tolerance) are shown in Table 3 . The mean IAUC of glucose was $175.91 \mathrm{mg} / \mathrm{dl}$ and IAUC of RH, RCS and RJ was 79.16 $\mathrm{mg} / \mathrm{dl}, 114.16 \mathrm{mg} / \mathrm{dl}$ and $108.33 \mathrm{mg} / \mathrm{dl}$ respectively. The mean IAUC of all the variety of rolls was considerably lower than glucose. It was observed that maximum reduction $(55.00 \%)$ in IAUC was exhibited by RH. When the mean reduction in IAUC of all the varieties roll was compared with glucose a highly significant reduction $(\mathrm{p}=$ $<0.002$ ) of IAUC was noted in case of RH. The mean IAUC of glucose was $319.16 \mathrm{mg} / \mathrm{dl}$ and the IAUC values observed for RH, RCS and RJ were $120.00 \mathrm{mg} / \mathrm{dl}, 121.66$ $\mathrm{mg} / \mathrm{dl}$ and $121.66 \mathrm{mg} / \mathrm{dl}$ respectively. The mean IAUC of all the variety of rolls was significantly lower than glucose but a highly significant reduction $(\mathrm{p}=<0.002)$ was noted in case of RH. The mean reduction in IAUC of all the varieties of rolls was compared with glucose. It was observed that maximum reduction $(62.40 \%)$ in IAUC was exhibited by RH (Table 4). GI of rolls was calculated and it was noted that GI values obtained for RH, RCS and RJ were 45.00, 64.89 and 61.58 respectively in case of normal healthy subjects. The mean GI of RH, RCS and RJ were found to be 37.59, 38.11 and 38.11 respectively in subjects with IGT. RH exhibited lowest GI values in normal as well as subjects with IGT.

\section{DISCUSSION}

A comparison of IAUC of RH with glucose in normal healthy subjects and subjects with IGT revealed a significant reduction of $55 \%$ and $62.40 \%$ respectively indicating that honey had no adverse effect on glycemic response and was well tolerated by subjects with IGT. These results suggest and support the statement that honey could be better than products made with cane sugar, which is a common sweetener in use ${ }^{9}$. Yet another study reported that honey has a gentler effect on blood sugar levels on a per gram basis, and tastes sweeter than sucrose so that fewer grams would be consumed, it would 
seem prudent to recommend honey over sucrose ${ }^{10}$. In this study consumption of all the varieties of sweet rolls by subjects with IGT as well as normal healthy subjects showed that rolls made with honey had lowest GI (GI value 37.59 and 45.00 In subjects with IGT and normal healthy subjects). This finding is supported by a study which reported that honey has lower glycemic index compared to many other carbohydrates ${ }^{11}$. According to the international table of glycemic index, honey has a GI value ranging between 32 and $87^{12}$. Most researches relating to the glycemic Index and health indicate the clinical usefulness of low GI in the treatment of diabetes and hyperlipidaemia. As the GI concept claims to predict the role of carbohydrates in the development of obesity ${ }^{13}$, low GI honeys might be a valuable alternative to high GI sweeteners. In the dietary management of diabetes or in proposing any food suitable for diabetic individual the grading of different foods in terms of a GI has been suggested to be very useful ${ }^{14}$. It is important to use foods that produce the least postprandial blood glucose variation and this has been observed with honey incorporated rolls in this study. IGT has been linked with an increased risk of cardiovascular events, and some analyses have demonstrated an increased mortality risk as compared to patients with normal glucose tolerance. IGT has been associated with other features of insulin resistance, including dyslipidaemia, hypertension, and abdominal obesity. It is also reported to be linked with micro albuminuria, endothelial dysfunction and markers of inflammation and hypercoagulability, traits collectively referred to as the metabolic syndrome. Analysis of combinations of these components have also been associated with progression to Type 2 Diabetes Mellitus, cardiovascular disease and increased mortality ${ }^{15}$. Therefore honey may be beneficial as sugar substitute for subjects with impaired glucose tolerance.

\section{CONCLUSION}

Honey incorporated food preparation having considerably low GI appear to be an alternative to sweet preparations usually made with cane sugar. Therefore it may be suitable for consumption, by people with impaired glucose tolerance and other health problems associated with poor blood glucose control in line with their dietary requirements in controlled amounts.

\section{REFERENCES}

1. Stefan Bogdanov, Tomislav Jurendic, Robert Sieber and Peter Gallmann. Honey for nutrition and health-a review. Journal of the American College of Nutrition 2008; 27(6): 677-689. http://dx.doi. org/10.1080/07315724.2008.10719745 PMid:19155427

2. Jenkins DJ, Wolever TM, Taylor RH, Barker H, Fielden H, Baldwin JM, Bowling AC, New HC, Jenkins AL, Goff DV. Glycemic index of food a physiological basis for carbohydrate exchange. Am J Clinical Nutrition 1981; 34(3): 362-366. PMid:6259925

3. Wolever TMS, Boume GH. The glycemic index aspects of some vitamins, minerals and enzymes in health and diseases. World Review Nutrition Diet 1990; 62: 120-185. PMid:2180214

4. White JW. Composition of honey. En: Crane E, ed. Honey a comprehensive survey. London Bee research Association and Chalfont St Peter; 1975. p. 157-206.

5. Ghosh AK and Agrawal MP. Gur grading based on physical and chemical constituants. Maharastra sugar 1983; 8(12): 39-43.

6. Srilakshmi B. Food Science. $5^{\text {th }}$ ed. New age international Pvt. Ltd. publishers; 2010. p. 289-319.

7. WHO/FAO A book of Carbohydrates in human nutrition, Report of an expert meeting jointly organized by the FAO of the United Nations and the WHO. FAO Food Nutrition Pap 1980 version-66 15: 1-82 (http://www.fao.org/docrep/W8079E/W8079E00.htm).

8. Gopalan C, Rama Sastri BV, Balasubramanian SC. Nutritive Value of Indian Foods. $14^{\text {th }}$ ed. National Institute of Nutrition, ICMR Hyderabad; 2011. p. 47-58.

9. Katsilambros NL, Philippides P, Touliatou A, Georgakopoulos K, Kofotzoul L, Frangaki D, Siskoudis P, Marangos M and Sfikakis P. Metabolic effects of honey (alone or combined with other foods) in type II diabetics. Acta Diabetologica latina 1988; 25(3): 197-203. http://dx.doi.org/10.1007/BF02624814 PMid:3071065

10. Shambaugh P, Worthington V, Herbert JH. Differential effects of honey, sucrose, and fructose on blood sugar levels. J Manipulative Physiological Therapeutics 1991; 14(1): 91-92. PMid:2002297

11. Abdulrhman M, El Hefnawy M, Hussein R. The glycemic and peak incremental indices of honey, sucrose and glucose in patients with type 1 diabetes mellitus: effects on C-peptide level - a pilot study. Acta Diabetologica 2011; 48(2): 89-94. http://dx.doi.org/10.1007 /s00592-009-0167-7 PMid:19941014

12. Wolever TMS, Brand Miller J, Robert SD. Measuring the glycemic index of foods inter laboratory study. Am J Clinical Nutrition 2008; 87(1): 247-257.

13. Ludwig D. Dietary glycemic index and obesity. J Nutr 2000; 130(2): 280-283.

14. Ionescu Tirgoviste C, Popa E, Sintu E, Mihalache N, Cheta D and Mincu I. Blood glucose and plasma insulin responses to various carbohydrates in Type 2 (Non-Insulin-Dependent) Diabetes. Diabetologia 1983; 24(2): 80-84. http://dx.doi.org/10.1007 /BF00297385 PMid:6341139

15. John L Petersen, Darren K Mcguire. Impaired glucose tolerance and impaired fasting glucose a review of diagnosis, clinical implications and management. J Diabetes and Vascular Disease Research 2005 2(1): 9-15. http://dx.doi.org/10.3132/dvdr.2005.007 PMid:16305067

Cite this article as:

Rana Seema, Katare Charu. Evaluation of honey incorporated food preparation on the basis of glycemic index and their advocacy in impaired glucose tolerance. Int. J. Res. Ayurveda Pharm. 2013;4(5):787790 http://dx.doi.org/10.7897/2277-4343.04531 